\title{
Commercial Real Estate Prices and Covid-19
}

\author{
Martin Hoesli* and Richard Malle ${ }^{* *}$
}

\section{Structured Abstract}

\section{Purpose}

The article analyzes the effects of the Covid-19 pandemic on commercial real estate prices, with a particular focus on European markets.

\section{Design/Methodology/Approach}

We start by highlighting caveats to bear in mind when referring to direct real estate indices. We then analyze the behavior of commercial real estate prices during the pandemic, emphasizing differences across property types. For that purpose, we use data for both direct and listed real estate. We further discuss changes in the main factors affecting commercial real estate pricing. The article then turns to discussing the likely trajectory of commercial real estate prices in the future.

\section{Findings}

We report that retail and hospitality properties and to a lesser extent office buildings have been affected the most by Covid-19, while the residential and industrial sectors have been less affected by the crisis. We maintain that the future trajectory of prices will vary across sectors and that the type and location of assets will become increasingly important in their valuation.

\section{Originality/Value}

This paper provides for a better understanding of the behavior of commercial real estate prices during the Covid-19 pandemic.

Keywords: Commercial real estate prices; Covid-19; Pandemic; Office; Retail; Hospitality JEL Codes: R33; G12; G2

\footnotetext{
* University of Geneva (Geneva School of Economics and Management and Swiss Finance Institute) and University of Aberdeen.

${ }^{* *}$ Conservatoire National des Arts et Métiers (CNAM) and BNP Paribas - Real Estate.
} 


\section{Introduction}

Commercial real estate is an attractive asset class for institutional investors. It offers stable income returns, its returns are weakly correlated with the returns of financial assets and the empirical evidence also points to its inflation-hedging effectiveness (Falkenbach and Hoesli, 2017). Against this background, several studies have documented the benefits of holding real estate assets in mixed-asset portfolios (Hoesli et al., 2004; MacKinnon and Al Zaman, 2009; Delfim and Hoesli, 2019).

The Covid-19 pandemic has affected some of the major factors influencing commercial real estate pricing. Rental streams have been significantly impacted. According to the World Tourism Barometer, for instance, international tourist arrivals declined by $65 \%$ during the first half-year of 2020 (UNWTO, 2020). This, together with a sharp decline in business travel, has led to much depressed hotel occupancy levels and often hotel closures. Retail incomes have also been severely hit by the pandemic. Due to lockdowns, in-store shopping was not possible in many locations, which led to the further increase in online retailing which had been growing fast even prior to the pandemic. The work from home policies that have been implemented in many regions have proved the effectiveness of such work organization, leading to concerns regarding the future of office space demand and hence of rental levels. The uncertainties on cash flows are likely to have led to an increase in risk premia and a decrease in growth expectations. These effects were mitigated by decreases in interest rates, leading to quite stable yields so far, at least in prime locations.

Several studies have analyzed the early-stage effects of the pandemic on commercial real estate prices. As such, the results cannot be extrapolated easily to gauge the long-term effects of Covid-19 on real estate prices. Ling et al. (2020) examine how U.S. Real Estate 
Investment Trust (REIT) returns are related to a geographically weighted exposure of their underlying assets to Covid-19 growth. They report a negative reaction of returns to such exposure. Firms focused on retail and residential properties react more negatively among all sectors, while healthcare and technology sectors are positively correlated with exposure to Covid-19 growth. Xie and Milcheva (2020) find negative effects of proximity to Covid-19 cases on the returns of Hong Kong real estate firms. Markets also perceive the risk to be higher in commercial buildings than in residential properties. Milcheva (2021) reports that the effect of Covid-19 is associated with steep declines in international real estate security returns and an increase in risk. Retail is found to have the highest sensitivity to Covid-19, whereas healthcare has the lowest sensitivity. Finally, van Dijk et al. (2020) use liquidity impacts at the onset of the pandemic to infer future price changes on direct markets. They predict that the retail sector will be most badly hurt with price declines in the $14-19 \%$ range. The industrial sector is predicted to be slightly more resistant with price drops in the $10-15 \%$ range.

Duca et al. (2021) focus on the effects of Covid-19 on housing markets. They report variance in the evolution of house prices across countries, with locations depending heavily on tourism showing declining house prices while prices elsewhere have generally continued to increase. They argue that the lack of a negative impact on house prices largely owes to the low interest rate environment and the smaller relative effect of the pandemic on upper income households, but also to behavioral factors. The latter relate to beliefs about the duration of the economic crisis that has been triggered by the pandemic and the prospects for recovery, the sentiment that housing is a good investment in the long run, and declines in the number of assets for sale due to loss aversion behavior. 
In this article, we seek to provide a better understanding of the reactions of commercial real estate prices during the Covid-19 crisis. We use direct real estate data for the U.S. and three European countries. We also use data for listed real estate in Europe. Given the greater efficiency of the listed market, such indices should make it possible to uncover more rapidly any changes in the pricing of commercial real estate assets. We focus on differences across property types. Caveats concerning direct real estate price indices that should be borne in mind are discussed. We also provide a discussion of the likely path of commercial real estate prices in the future, with again a focus on differences across property types.

Our analyses reveal that the hospitality and retail sectors have been affected the most by the crisis. Structural changes that are taking place in the retail market are also visible. Although the office market has not been affected as badly as retail properties and hotels, price decreases remain significant and are likely indicative of shifts in work patterns, in particular the prospects for the development of work from home policies. Property prices in other sectors, in particular in the residential and logistics sectors, have been less affected, if at all, by the crisis. Using the current economic forecasts, we maintain that prices for commercial real estate assets are likely to increase in some market segments, in particular prime offices, for the years to come. However, as far as non-prime assets are concerned, decreases in values could occur in the short- to medium-term. The prospects for logistics and residential real estate are usually good, whereas the picture is more nuanced for retail properties and hotels. In the future, we believe that the characteristics of assets should play a stronger role in their valuation. 
The remainder of the paper is structured as follows. The next section highlights some caveats to bear in mind when using direct real estate indices. The following section discusses changes in commercial real estate prices and their driving factors since the onset of the Covid19 crisis. We then turn to providing an outlook for the economy and commercial real estate markets. Some concluding remarks are provided in a final section.

\section{Caveats Concerning Direct Real Estate Price Indices}

A customary way of producing commercial real estate indices is to rely on the regular appraisal of a set of representative properties. The capital change component of the index is calculated on the basis of the change in the estimated property values, taking into account any capital expenditures incurred during the period. Much research has documented the smoothing and lagging of those types of indices (Delfim and Hoesli, 2021). If a proper adjustment is not undertaken, real estate risk will be understated and turning points assessed incorrectly. The MSCl indices that we use below for the U.K., France and Italy are appraisalbased indices.

Another increasingly popular way of tracking price changes on commercial real estate markets is to rely on the repeat sales method (Bailey et al., 1963). This approach relies on transactions data, rather than appraisal data, and focuses on the price changes of properties that have been sold at least twice during a given period. A regression framework is used and the estimated coefficients on the time variables make it possible to construct the index. Potential biases with this approach include the facts that the quality of properties can change between two sales (for instance, if there is a refurbishment) and the number of repeat sales on a given market can be limited. This latter concern is exacerbated in a crisis period given 
that transaction volumes tend to decline markedly. The CoStar indices that we use below for the U.S. market are constructed using this approach.

Direct real estate indices suffer also from the so-called escrow lag, i.e., the fact that prices recorded at a given point in time are likely to have been agreed upon several months before. This interval is largely related to the time that is needed for the due diligence process to take place. Hoesli et al. (2015), for instance, use a 90-day escrow lag for their analyses of U.S. commercial real estate markets. Quarterly index values as of June 2020 , and in some cases even September 2020, are affected by prices which had been agreed upon prior to the start of the pandemic. Also, given the crisis, index values are based on the evidence provided by limited volumes of transactions. Hence, caution has to be exercised as to not over interpret direct real estate price changes. This is compounded by the short history of commercial real estate price changes since the beginning of the pandemic.

As mentioned above, we use CoStar indices for the U.S. The indices are price indices and are available at the quarterly frequency for the various sectors. For the U.K., France and Italy, we use the capital return indices produced by MSCI. The U.K. indices are at the monthly frequency, whereas the indices for the other two countries are annual. As a result of being calculated on the basis of appraisal-based indices, capital returns suffer from smoothing and hence exhibit high levels of serial correlation. For the various property types, the serial correlation of U.K. commercial real estate capital returns is in the range from 0.511 (hotels) to 0.883 (industrial). For France, the figures are in the range from 0.336 (office) to 0.575 (retail). For Italy, the lowest serial correlation is 0.544 (retail) and the highest correlation is 0.672 (industrial). Returns are desmoothed using a reverse filter (Geltner, 1993). The aim is to reduce the level of serial correlation to a level that is comparable to that observed for returns 
calculated by means of transaction-based indices. For U.K. returns, we use a desmoothing parameter of 0.3 for hotels and 0.7 for the other types of properties. This results in desmoothed capital return series with serial correlations between 0.167 (hotels) and 0.265 (offices). We use a desmoothing parameter of 0.4 for France and 0.3 for Italy. The desmoothed capital returns have a serial correlation from 0.073 (offices in Italy) to 0.365 (industrial in Italy).

\section{Real Estate Prices and Covid-19}

Although much alarming news concerning Covid-19 was emerging from China during January 2020, most people in Europe and the U.S. started realizing in February only that the disease was likely to affect their regions too. By the second half of February, there were a number of confirmed cases in several European countries. On March 11, the World Health Organization declared the crisis a pandemic. These developments led to many countries enforcing restrictions to the movement of people across countries and sometimes also within countries. Some countries introduced strict lockdowns; France and Italy being good examples. This had immediate effects on the income generated by many types of properties, in particular retail and hospitality real estate. In-store sales were often abruptly stopped and much retailing activity switched to online, leading to a jump in rent non-payments and an acceleration of the trend towards online retailing that had started several years ago. The increased demand from e-commerce companies in search of hubs to dispatch goods to customers benefited logistics properties. The effects on prices were exacerbated by the low completed and under construction supply of properties in main locations. As for hotels, both leisure and business travel were significantly affected, leading to low occupancy rates or hotel 
closures. It is also likely that risk premia were affected, as they were at the onset of the global financial crisis (Duca and Ling, 2020).

Focusing first on U.S. commercial real estate prices (Figure 1), we observe some variance in price developments at the onset of the Covid-19 crisis. Whereas hospitality and retail prices declined at the start of the pandemic, no effect can be seen for the other sectors, even when data up to the first quarter of 2021 are taken into consideration. While hospitality prices have been declining for a full year now, retail prices are now higher than their levels prior to the pandemic, suggesting that in the U.S. the hospitality sector has been the hardest hit by the crisis. Figure 2 depicts the desmoothed capital return indices for the U.K. Values in all sectors except the industrial sector have been significantly affected by the crisis. Retail values have been declining since the beginning of 2018 , with the crisis accelerating the drop. Industrial values briefly declined at the onset of the pandemic and then started rising again, suggesting that this sector benefited from the structural changes that have been taking place since the start of the pandemic. For France and Italy (Figure 3), both retail and office values were negatively affected by the crisis, whereas industrial values were stable. Caution should be exercised, however, as the indices for those two countries are annual and hence only one data point is available since the pandemic started (that for year 2020).

Price variations are generally consistent with changes in pricing fundamentals for the various market segments. Office values have been so far quite resistant, with limited decreases in rental incomes and pretty stable yields. In Paris, for instance, prime rents have increased slightly, but so have vacancy rates (BNP Paribas Real Estate, 2021b). Average rents, however, have declined. Despite increasing risk and lower investment activity, yields for prime and core assets decreased slightly as a result of lower risk-free interest rates and flight 
to quality (BNP Paribas Real Estate, 2021a). As of 2020Q4, net prime office yields in Paris were at $2.70 \%$. For London, yields and prime rents have been stable; however, values declined somewhat due to higher vacancy rates.

The effects of the lockdowns were felt most acutely in the retail and hotel sectors, with large decreases in rental incomes. Increases in the risk premia more than offset any benefits from declining risk-free interest rates. This led to those two sectors being most affected by the pandemic. Industrial and logistics values were more resistant and sometimes even increased in the last few months. Rental incomes were not affected severely by the pandemic, whereas yields decreased slightly or were stable. This is consistent with a pattern of retailing activity shifting more significantly to e-commerce and the demand for logistics space to supply the goods.

Those conclusions hold by and large when the various sectors of the securitized real estate market are analyzed. Such analysis is useful as much research has shown that, given its greater information efficiency, the listed real estate market reacts more quickly to changes in fundamentals than does the direct market (Hoesli and Oikarinen, 2012; Ling and Naranjo, 2015; Hoesli and Oikarinen, 2021). Hence, the listed real estate market should uncover any price developments before the direct market.

We use the EPRA Developed Europe price indices for six sectors (Figure 4). The indices are set at 100 as of February 21, 2020. This is the last trading day before the first lockdowns were enforced in some Northern Italy municipalities on February 23 and it was getting quite clear by then that Europe was headed for a crisis. Figure 4 shows that there are marked differences across sectors. The price of lodging/resort properties dropped the most at the onset of the crisis (the drop was almost $80 \%$ ). The loss in value stabilized thereafter at about 
$50 \%$ and then was reduced in November 2020 with the positive announcements concerning the development of a vaccine. As of mid-June 2021, the loss in value relative to the value on February 21,2020 is about $30 \%$. The pricing reflects the uncertainties about the future of the travel industry, in particular whether business travel will ever revert to its pre-crisis levels. The retail sector was not affected quite as badly as the hotel sector, but drops in value continued for several months, reflecting the structural changes that are occurring in the sector. As is the case for hotels, the encouraging news regarding the development of a vaccine led to significant price gains in November.

The office sector was not as affected as the hotel and retail sectors, but decreases in values still amounted to more than $40 \%$ at the onset of the pandemic. This is likely due to the expectation that there will be less demand for office space even after the pandemic as a significant share of work from home is likely to remain. As in any crisis, there is also a fear of rising unemployment levels. It could also be due to some extent to the securitized real estate market overestimating the post Covid-19 shifts in demand. The healthcare sector was slightly less affected by the crisis, but prices still dropped by $35 \%$ at the onset on the crisis. Price losses had stabilized at about $10 \%$ by the end of the time period. The losses in value are likely a reflection of the classical medical activity being significantly affected as many non-essential surgeries did not take place during the pandemic. There were also high mortality rates in retirement homes. Many families whose elderly members were on a waiting list to enter such facilities opted not to accept an offer to move into such homes as rooms became available, leading to lower occupancy rates. Although prices dropped significantly at the onset of the crisis in the residential and industrial sectors, they had more than regained their losses by midJune 2021. Demand for residential space is strong, with signs of some households seeking 
larger units as a result of the crisis (Duca et al., 2021). As discussed above, the demand for logistics space has often increased as a consequence of the shift from physical retailing to online shopping, leading to logistics prices being 15\% higher in mid-June 2021 than at the start of the crisis.

\section{Economic and Property Outlook}

This section analyzes trends in Gross Domestic Product (GDP) and interest rates as well as forecasts for commercial real estate markets. Our timeframe is from 2021 to 2025 to simulate a medium-term trend in the wake of the Covid-19 crisis, in line with the forecasts available to us. For GDP and interest rate forecasts, we use Consensus Forecasts published by Consensus Economics Inc. (2021), which provides an average of forecasts from the main international economic institutions. In April and October of each year, five-year forecasts are published for the main economic components. For real estate, we use BNP Paribas Real Estate sources, which generate forecasts from the economic scenarios issued by Consensus Forecasts.

GDP affects the profitability of real estate markets, mainly by influencing the demand for office space (Benjamin et al., 2001). For most countries, GDP contracted very sharply during 2020. From 2021 onwards, assuming a better control of the pandemic, increased immunity of the population through vaccination and the easing of health restrictions, economic growth is expected to be positive. However, most European countries will only return to their pre-crisis (2019) wealth generation levels in 2022-2023, while for the U.S. this could be as soon as 2021 thanks to a faster restart in activity. As such, after the major shock to the economy in 2020 , this base case scenario points to a robust trend in terms of employment, investment and consumption from 2021 onwards. Of course, this consensus 
scenario entails uncertainty and could be adjusted either upward to reflect higher levels of consumer and company confidence, or downward in case of a resurgence of the pandemic. Our property forecasts below are built from the base case economic scenario.

Interest rates play a fundamental role in the valuation of investment properties (Johnson, 2000). Indeed, the initial yield can be calculated as the sum of the risk-free yield, generally reflected by the 10 -year government bond yield, and a risk premium. Moreover, investment properties are valued customarily using the income approach, with a discount rate that also depends on the risk-free rate (see, e.g., Brueggeman and Fisher, 2019). Ten-year bond yields hit a historical low at the end of 2020 (-0.3\% in France, $0.2 \%$ in the U.K., $0.5 \%$ in Italy and $0.9 \%$ in the U.S.). Countries became very heavily indebted during 2020 to help finance the impact of health measures and support economic activity (International Monetary Fund, 2020). These government-issued debts were largely absorbed by Quantitative Easing policies, which can be defined as an expansionary monetary policy aimed at buying financial instruments, such as government bonds, to stimulate the economy (Joyce et al., 2012). From 2021, Consensus Forecasts sees government bond yields rising, albeit still only to historically low levels.

Like bond yields, initial prime office yields changed little in Europe from 2019 to 2020 in countries such as the U.K., France and Italy (Figure 5). The crisis could have led to a sharp increase in prime office yields, as occurred during the 2009 financial crisis, but the resilience can be explained by several factors. First, demand for prime office assets has been fueled by the abundance of liquidity and the quest for guaranteed assets. Another consideration is that the yield gap, calculated as the difference between initial real estate yields and the risk-free rate, reached sufficient levels in 2020 to compensate for the additional risk following the 
Covid-19 crisis. As of the end of 2020, the yield gap stood at $3.3 \%, 3.0 \%$ and $2.7 \%$ in London, Paris and Milan, respectively, compared to averages of $1.9 \%, 2.3 \%$ and $1.1 \%$ over the 2010 2019 period. This is why, according to BNP Paribas Real Estate data, initial prime office yields over the 2021-2025 period should contract in Paris (-20 basis points), Milan (-30 basis points), and even London (-35 basis points) thanks to a clearer overall situation (including less uncertainty around Brexit). However, the yields for riskier office assets (which may have shortcomings in terms of location, quality of the premises, or rental status) are set to increase, although this is hard to quantify due to both the lack of recorded transactions and the heterogeneous nature of these assets.

Figure 6 shows the prime office rent trend for London, Paris and Milan. The robust economic growth expected from 2021 as well as controlled supply levels in the main European business districts should lead to resiliency in prime rents, despite the economic and health context. From 2020 to 2025 , prime rents are expected to remain pretty stable in Paris and Milan ( $+3 \%$ and $+0 \%$ respectively, after increasing by $+13 \%$ in Paris and $+25 \%$ in Milan over the $2015-2020$ period), while they are forecast to increase by $12 \%$ in London. Applying a simple direct capitalization valuation method, i.e., calculating the ratio between the expected change in rents and the change in yields for prime office assets from 2020 to 2025, gives us an estimate of the possible trajectory of asset values. Prices could record a surge in London $(+24 \%)$, while increasing more moderately in Paris (+12\%) and Milan (+10\%).

These outlooks may seem counterintuitive given the steep decline in rental demand and the rise in teleworking that has reduced the need for office space since the Covid-19 crisis. Nevertheless, the rigidity of leases is a factor that limits supply and rental variations as companies must wait for their leases to end before relocating and possibly reducing their floor 
areas. Furthermore, it is exceedingly hard to gauge the degree to which teleworking will be used once the health crisis is over, and this will depend on each company in terms of its location, size, business sector and corporate culture. Rents and prices in non-prime locations are likely to see a more downward trend over the next five years, with some outlying areas less sought after or even shunned by companies.

For retail, investors may therefore demand higher risk premiums, implying higher initial yields and lower prices until the pandemic is fully under control. The fall in the value of prime retail assets could be reversed when the health measures come to an end and once domestic and international demand is restored close to pre-crisis levels. This could be in 2022 or 2023, considering the delayed and uncertain effect between the lifting of travel constraints and the return of distant consumers. We note that the initial prime yields of street-level stores are showing a historical anomaly insofar as they are equal to or greater than those of offices, with differences of 0 basis points in the U.K., +20 basis points in Italy and +45 basis points in France at the end of 2020 , compared to average differences of $-43,-19$ and -29 basis points, respectively, over the $2010-2019$ period. As yields are expected to be very low for 10 -year bonds from 2021 to 2025 and with further declines for initial prime office yields, the initial yields for prime street-level stores may diminish considerably, which would boost the capital values of these assets. On the other hand, an increase in the capital values of shopping centers and out-of-town retail looks more doubtful following the health crisis. In contrast to high streets, the stock of shopping centers and out-of-town retail has been rising continuously, with growth estimated at an annual average of $1 \%$ in the U.K., $1.7 \%$ in Italy and $1.8 \%$ in France over the 2010-2019 period (Source: BNP Paribas Real Estate, PMA). 
The outlook for the hotel market depends on many of the same factors as retail. The continued health measures together with their immediate and delayed effects on domestic and international travel, both professional and private, will dampen hotel performances. Hotels with the best locations and the most stars should be revived following the health crisis. At the other end of the scale, some facilities are likely to close given the length of the crisis. Also, much doubt remains concerning the extent to which domestic and international professional travel will recover, as many trips may be replaced by remote meetings, to save time and travel costs for companies. As such, many hotels may never revert to their pre-crisis occupancy rates.

The capital value trend for industrial assets may well be upward over the 2021-2025 period, after having been resistant in 2020. This situation observed during the Covid-19 crisis differs greatly from that during the financial crisis of 2009 , when prices fell sharply as in the U.K. (-41\% between July 2007 and July 2009, Figure 2). There will be two lasting differences for logistics after 2020, namely controlled levels of supply in most markets and continued strong demand from retail and particularly e-commerce players. Prime rents are therefore expected to rise in Europe from 2021 to 2025 (annual average of $+1.5 \%$ per year), after having significantly increased already from 2015 to 2020 (+2.5\%). Initial prime yields in logistics may narrow further in the coming years throughout Europe (-35 basis points expected between 2020 and 2025). This is all the more remarkable in that these yields were already at historically low levels at the end of 2020 (-148 basis points compared to their 2010-2019 average, vs. 112 and -27 basis points for offices and retail, respectively). These assumptions suggest that the price of prime logistics assets in Europe may rise by $+16 \%$ from 2020 to 2025 . 
Finally, residential real estate prices have been stable, in both Europe and the U.S., despite a fall in sales volumes due to the repeated health constraints throughout 2020 . The main pre-crisis fundamentals remain unaffected and should underpin demand in most cities, namely rising revenues and demographics, as well as very favorable borrowing conditions with interest rates low over the long term. Furthermore, as people have been spending longer at home since the outbreak of Covid-19, their wellbeing there has become more important. Households may therefore assign greater value to properties according to their characteristics (location, nearby services and retail, sunshine, size, number of rooms, etc.), even earmarking more of their budget to spending on the home, which will underpin price rises.

\section{Conclusions}

Our analyses reveal that the hospitality and retail markets and to a lesser extent the office sector have been affected the most by the Covid-19 pandemic. Prices have been more resistant in other sectors. Although the pandemic has clearly affected commercial real estate prices, it is important to bear in mind that the available data since the outburst of the pandemic cover a short period only and hence caution has to be exercised not to overinterpret the price changes.

The future of commercial real estate prices will largely depend on the state of the macroeconomy and whether the vaccines and drugs prove effective in eradicating the pandemic. So far, aided by strong fiscal and monetary policy counter measures, macroeconomies have generally performed better than the dire economic forecasts made in the spring of 2020. However, it is unclear how much longer governments will be able to borrow to support businesses and households through the downturn. It is also unclear how much more and how fast shopping patterns, work from home policies and business travel will 
evolve in the years ahead. Stated differently, it is hard to disentangle the permanent effects of the pandemic on the real estate sector from the transitory ones.

Bearing those uncertainties in mind, we maintain that valuations of real estate assets will take varying trajectories in the future. Overall, prospects are better for industrial and residential real estate and to a lesser extent offices than for retail and hotel properties. Prices are likely to depend more heavily and more narrowly on the type and location of the assets, while current and future rental conditions should be taken into account to a greater extent in the risk premium. Consequently, financial markets may struggle to value listed property companies, and such valuations may become more volatile over the next few years. The many uncertainties concerning the long-term effects of the pandemic on commercial real estate values certainly leave researchers and the real estate industry with many important and interesting issues to grapple with in the years ahead. 


\section{References}

Bailey, M. J., Muth, R. F. and Nourse, N. O. (1963), “A regression method for real estate price index construction", Journal of the American Statistical Association, Vol. 58, pp. 933-942.

Benjamin, J. D., Sirmans, G. S. and Zietz, E. N. (2001), "Returns and risk on real estate and other investments", Journal of Real Estate Portfolio Management, Vol. 7 No. 3, pp. 183-214.

BNP Paribas Real Estate (2021a), At a Glance - European Capital Markets - Q4 2020, BNP Paribas Real Estate, Paris.

BNP Paribas Real Estate (2021b), At a Glance - Main Office Markets in Europe - Q4 2020, BNP Paribas Real Estate, Paris.

Brueggeman, W. and Fisher, J. (2019), Real Estate Finance and Investments, $16^{\text {th }}$ edition, McGraw-Hill-Irwin Series, New York.

Consensus Economics Inc. (2021), Consensus Forecasts: Surveys of International Economic Forecasts, October.

Delfim, J.-C. and Hoesli, M. (2019), "Real estate in mixed-asset portfolios for various investment horizons", Journal of Portfolio Management, Vol. 45 No. 7, pp. 141-158.

Delfim, J.-C. and Hoesli, M. (2021), "Robust desmoothed real estate returns", Real Estate Economics, Vol. 49 No. 1, pp. 75-105.

Duca, J. V., Hoesli, M. and Montezuma, J. (2021), "The resilience and realignment of house prices in the era of Covid-19", Journal of European Real Estate Research, https://doi.org/10.1108/JERER-11-2020-0055.

Duca, J. V. and Ling, D. C. (2020), "The other (commercial) real estate boom and bust: The effects of risk premia and regulatory capital arbitrage", Journal of Banking and Finance, Vol. 112, Article 105317.

Falkenbach, H. and Hoesli, M. (2017), "Real estate investing: Opportunities and challenges", Bankers, Markets and Investors, No. 148, pp. 3-16. 
Geltner, D. (1993), "Estimating market values from appraised values without assuming an efficient market", Journal of Real Estate Research, Vol. 8 No. 3, pp. 325-345.

Hoesli, M., Lekander, J. and Witkiewicz, W. (2004), "International evidence on real estate as a portfolio diversifier", Journal of Real Estate Research, Vol. 26 No. 2, pp. 161-206.

Hoesli, M. and Oikarinen, E. (2012), “Are REITs real estate: Evidence from international sector level data", Journal of International Money and Finance, Vol. 31 No. 7, pp. 1823-1850.

Hoesli, M. and Oikarinen, E. (2021), "Does listed real estate behave like direct real estate? Updated and broader evidence", Applied Economics, Vol. 53 No. 26, pp. 3023-3042.

Hoesli, M., Oikarinen, E. and Serrano, C. (2015), "Do public real estate returns really lead private returns?", Journal of Portfolio Management, Vol. 41 No. 6, pp. 105-117.

International Monetary Fund (2020), World Economic Outlook: A Long and Difficult Ascent, October.

Johnson, R. R. (2000), "Monetary policy and real estate returns", Journal of Economics and Finance, Vol. 24 No. 3, pp. 283-293.

Joyce, M., Miles, D., Scott, A. and Vayanos, D. (2012), "Quantitative easing and unconventional monetary policy - an introduction", The Economic Journal, Vol. 122, pp. 271-288.

Ling, D. C. and Naranjo, A. (2015), "Returns and information transmission dynamics in public and private real estate markets", Real Estate Economics, Vol. 43 No. 1, pp. 163-208.

Ling, D. C., Wang, C. and Zhou, T. (2020), "A first look at the impact of Covid-19 on commercial real estate prices: Asset-level evidence", Review of Asset Pricing Studies, Vol. 10 No. 4, pp. 669-704.

MacKinnon, G. H. and Al Zaman, A. (2009), "Real estate for the long term: The effect of return predictability on long-horizon allocations", Real Estate Economics, Vol. 37 No. 1, pp. 117-153.

Milcheva, S. (2021), "Volatility and the cross-section of real estate equity returns during Covid19", Journal of Real Estate Finance and Economics, https://doi.org/10.1007/s11146-021$\underline{09840-6}$. 
UNWTO (2020), World Tourism Barometer, August/September, Vol. 18 No. 5, World Tourism Organization, Madrid.

Van Dijk, D., Kinsella Thomson, A. and Geltner, D. (2020), "Recent drops in market liquidity may foreshadow major drops in US commercial real estate markets", working paper, SSRN, https://papers.ssrn.com/sol3/papers.cfm?abstract id=3604606.

Xie, L. and Milcheva, S. (2020), "Proximity to Covid-19 cases and real estate equity returns", working paper, SSRN, https://papers.ssrn.com/sol3/papers.cfm?abstract id=3641268. 
Figure 1: Commercial Real Estate Prices in the U.S.

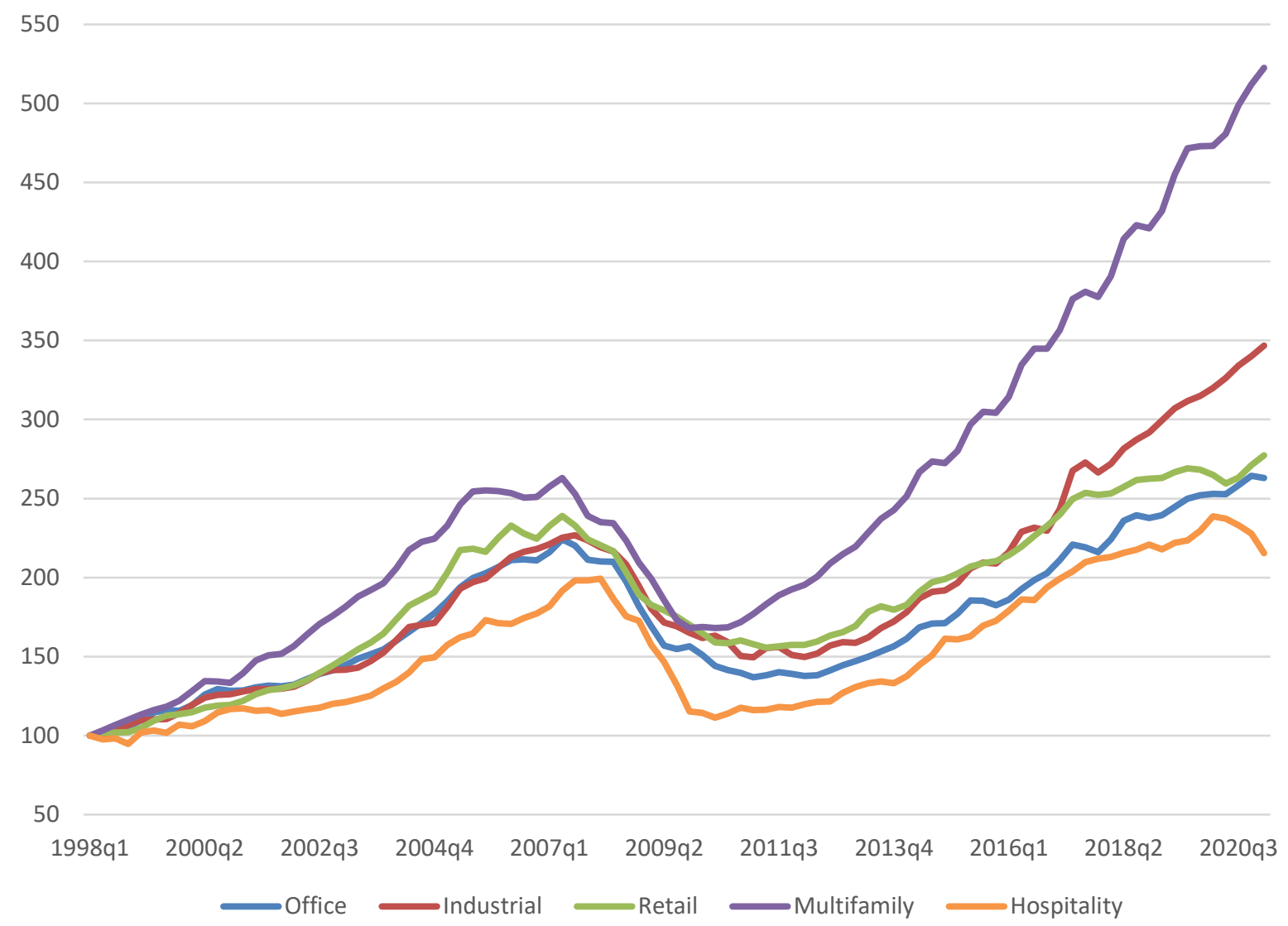

Sources: CoStar and authors' calculations. 
Figure 2: Commercial Real Estate Prices in the U.K. (Desmoothed)

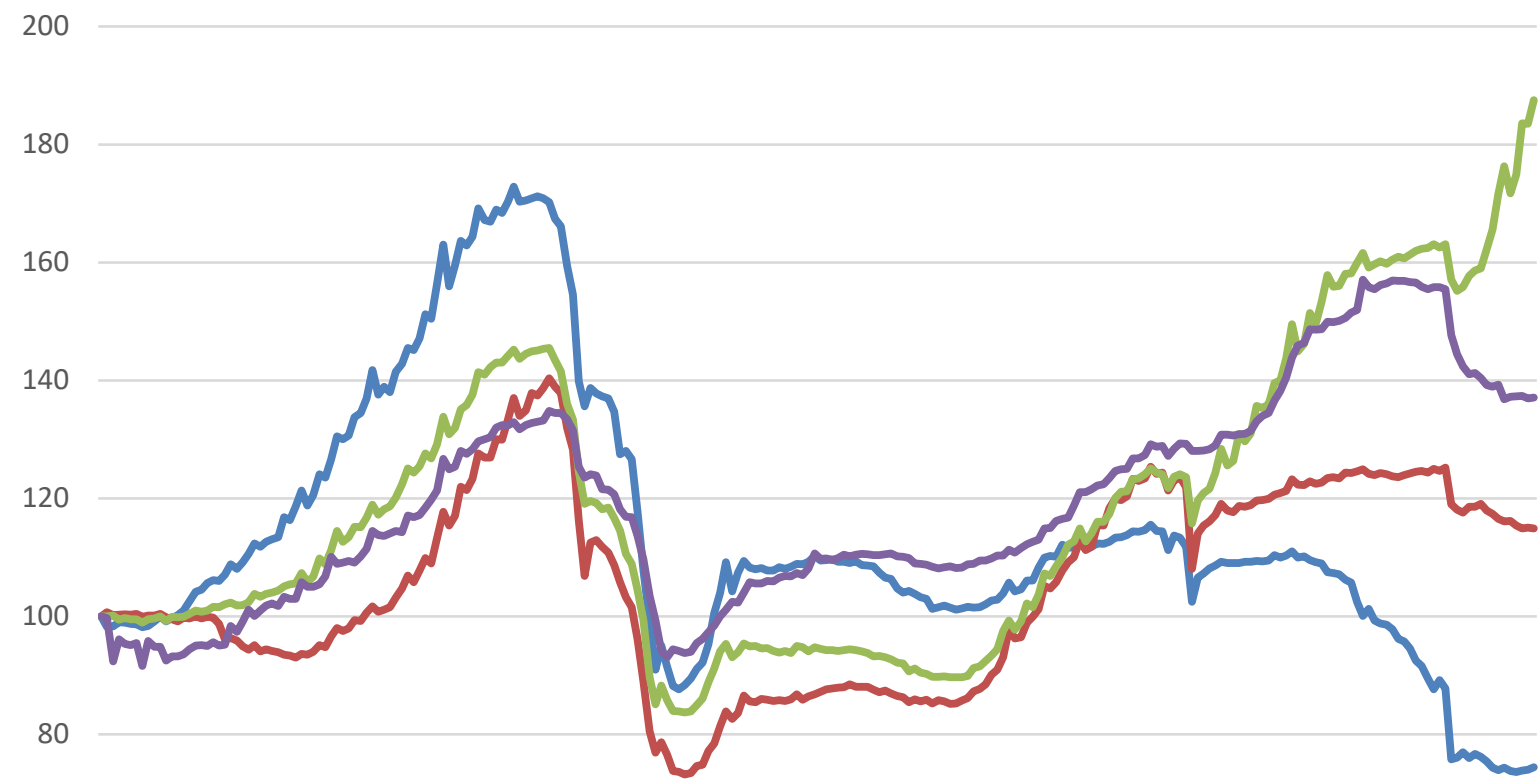

60

40

Feb 2001 Feb 2003 Feb 2005 Feb 2007 Feb 2009 Feb 2011 Feb 2013 Feb 2015 Feb 2017 Feb 2019 Feb 2021

$\longrightarrow$ Retail $\longrightarrow$ Office $\longrightarrow$ Hotel

Sources: $\mathrm{MSCl}$ and authors' calculations. 
Figure 3: Commercial Real Estate Prices in France and Italy (Desmoothed)

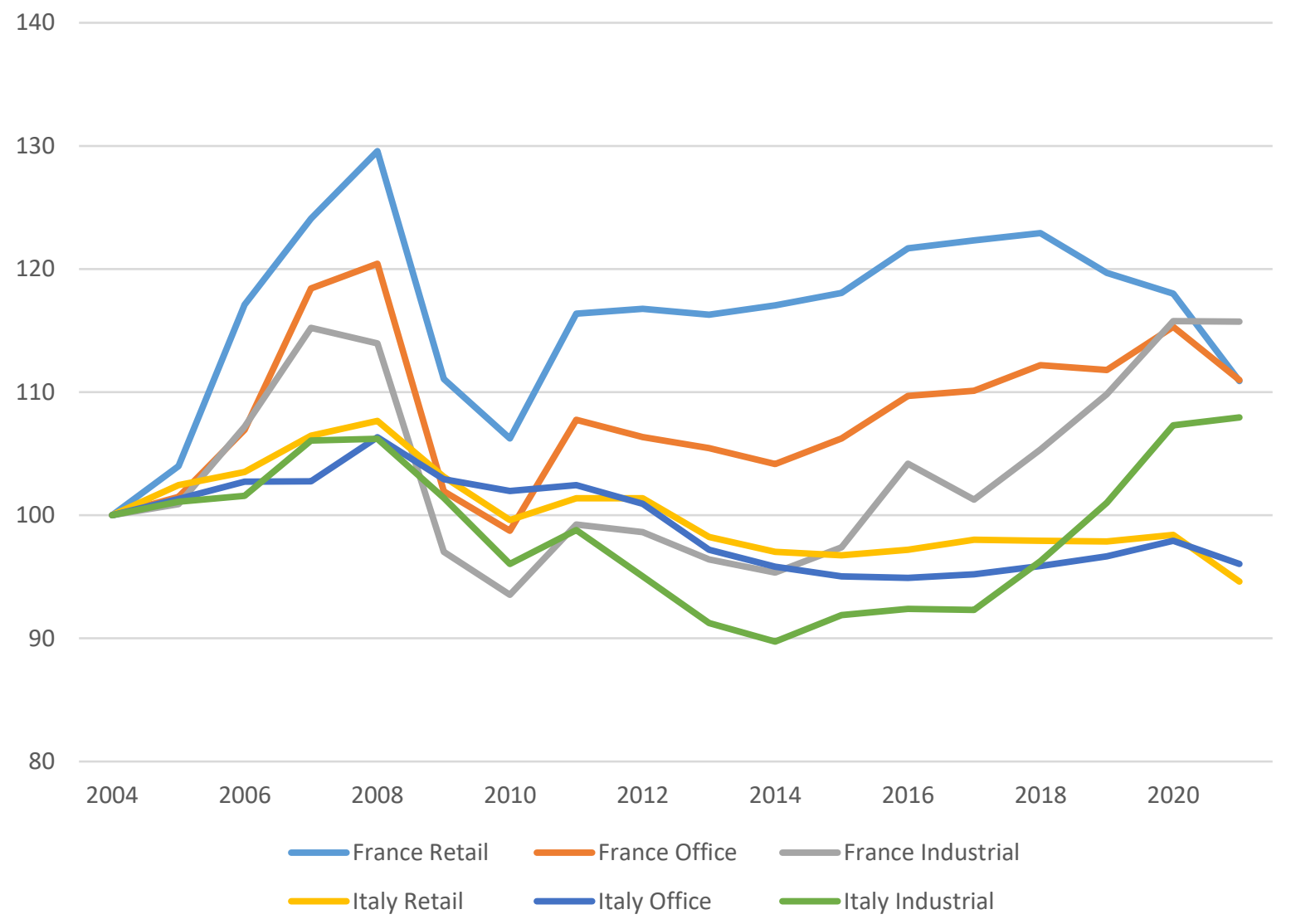

Sources: $\mathrm{MSCl}$ and authors' calculations. 
Figure 4: Listed Real Estate Price Indices (Developed Europe)

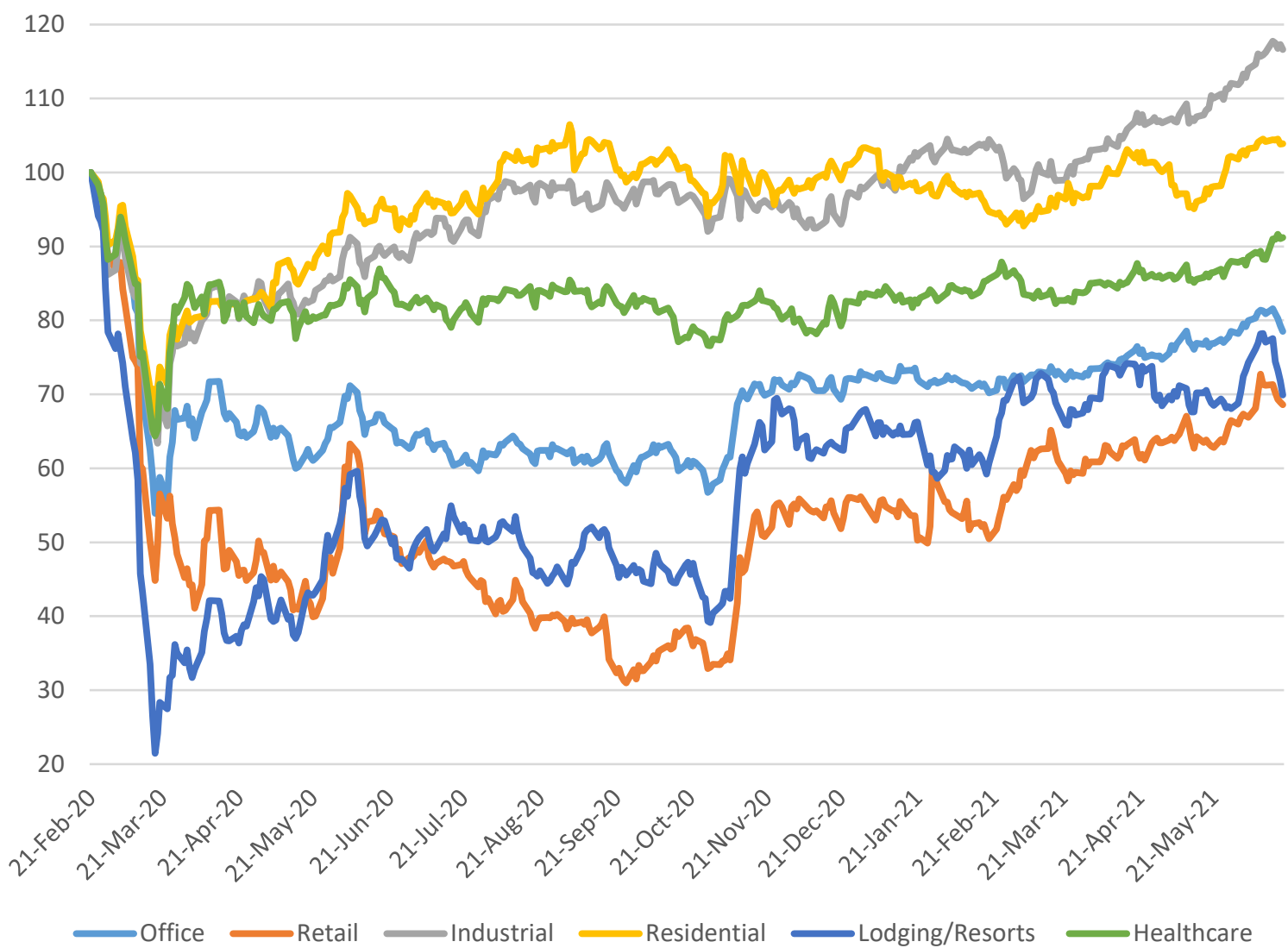

Sources: EPRA and authors' calculations. 
Figure 5: Office Prime Initial Yield Outlook

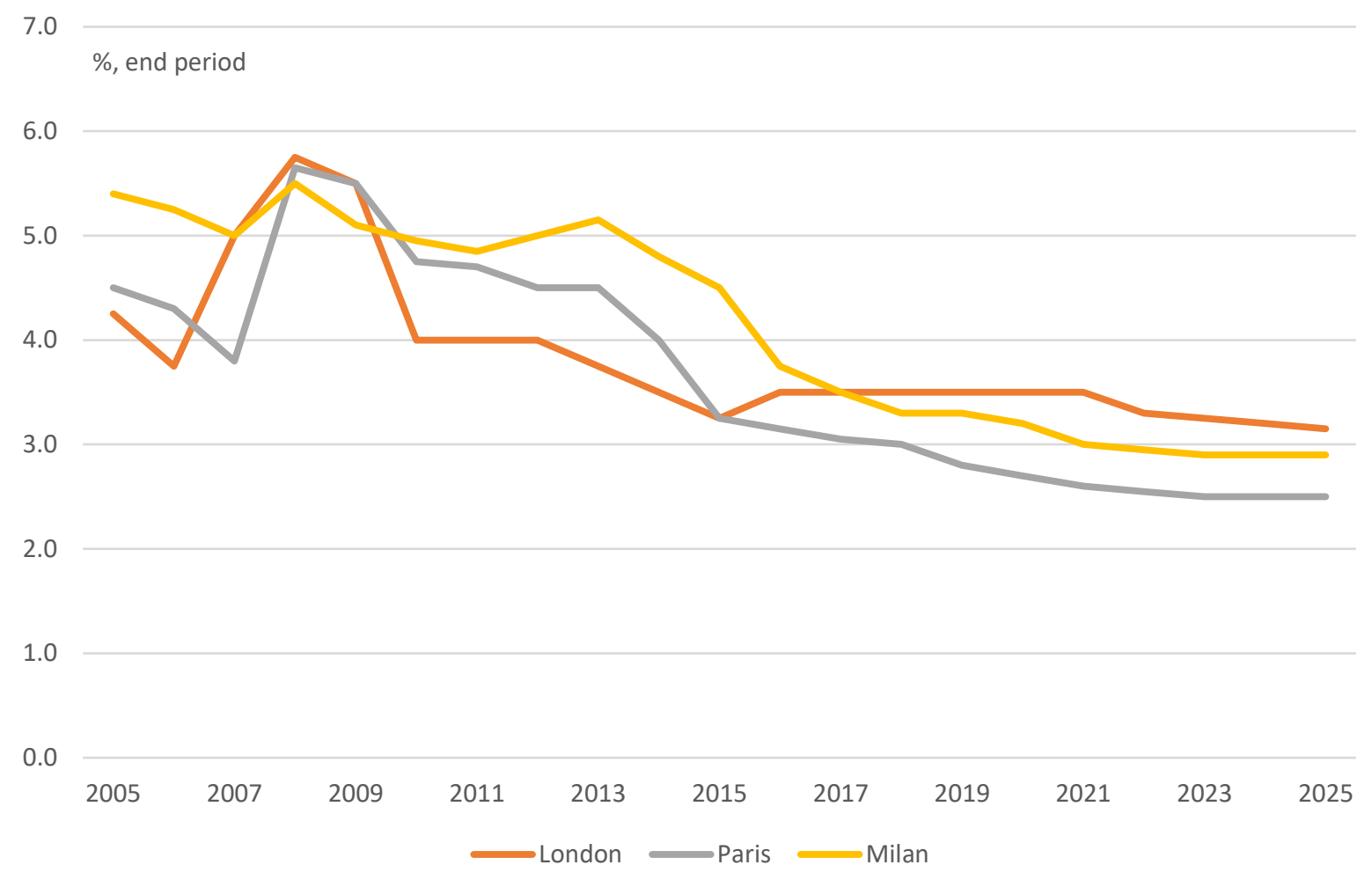

Source: BNP Paribas Real Estate Research (forecasts for 2021-2025). 
Figure 6: Office Prime Rent Outlook

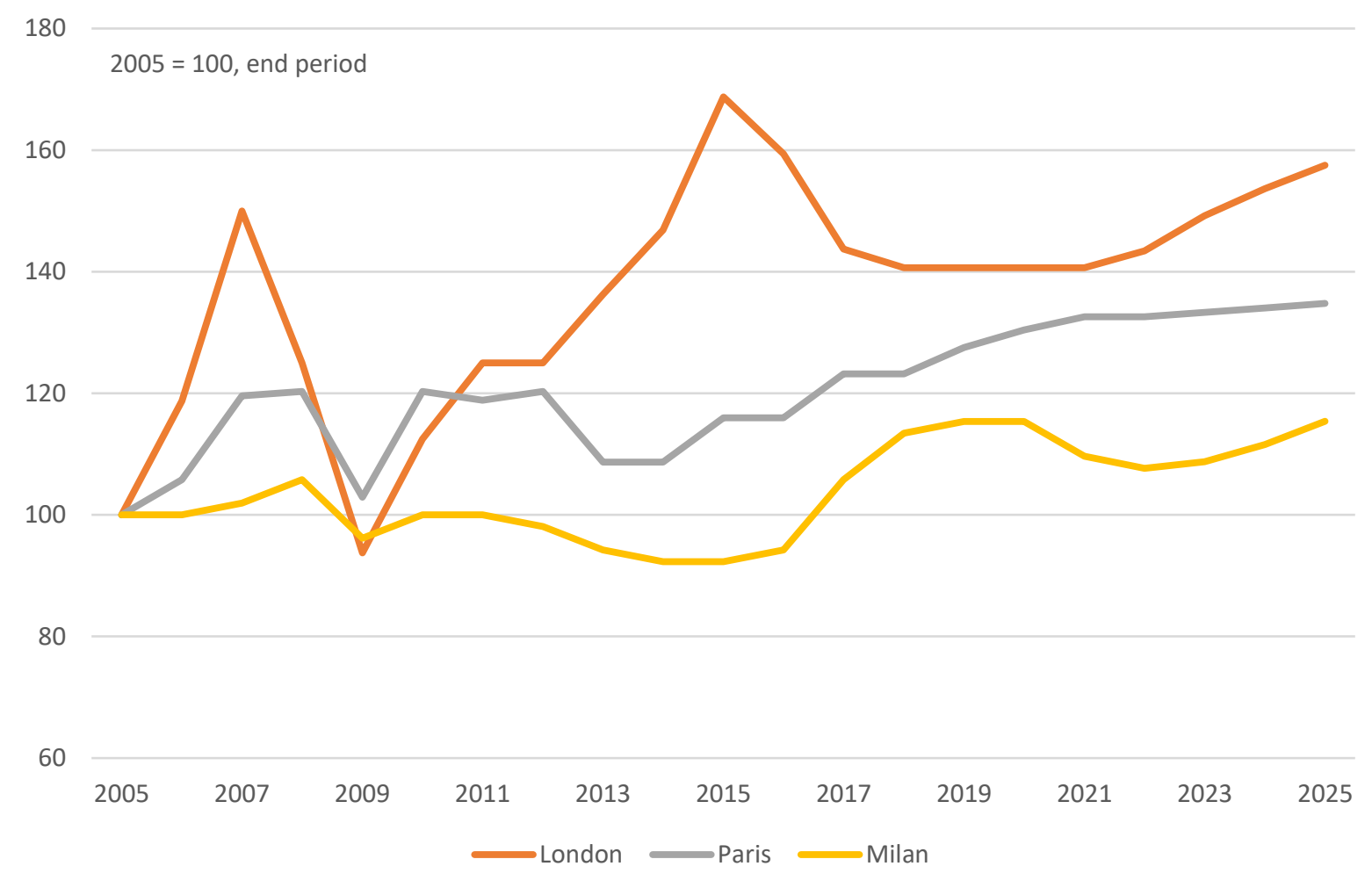

Source: BNP Paribas Real Estate Research (forecasts for 2021-2025). 